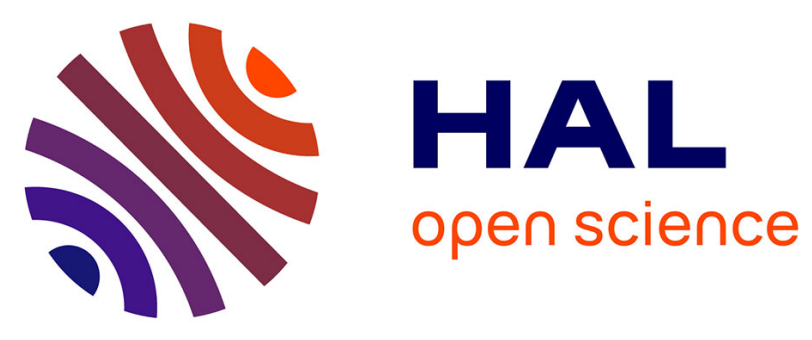

\title{
The All-Seeing Eye of Resonant Auger Electron Spectroscopy: A Study on Aqueous Solution Using Tender X-rays
}

Tsveta Miteva, Nikolai Kryzhevoi, Nicolas Sisourat, Christophe Nicolas, Wandared Pokapanich, Thanit Saisopa, Prayoon Songsiriritthigul, Yuttakarn Rattanachai, Andreas Dreuw, Jan Wenzel, et al.

\section{To cite this version:}

Tsveta Miteva, Nikolai Kryzhevoi, Nicolas Sisourat, Christophe Nicolas, Wandared Pokapanich, et al.. The All-Seeing Eye of Resonant Auger Electron Spectroscopy: A Study on Aqueous Solution Using Tender X-rays. Journal of Physical Chemistry Letters, 2018, 9 (15), pp.4457-4462. 10.1021/acs.jpclett.8b01783 . hal-01847985

\section{HAL Id: hal-01847985 \\ https://hal.sorbonne-universite.fr/hal-01847985}

Submitted on 24 Jul 2018

HAL is a multi-disciplinary open access archive for the deposit and dissemination of scientific research documents, whether they are published or not. The documents may come from teaching and research institutions in France or abroad, or from public or private research centers.
L'archive ouverte pluridisciplinaire HAL, est destinée au dépôt et à la diffusion de documents scientifiques de niveau recherche, publiés ou non, émanant des établissements d'enseignement et de recherche français ou étrangers, des laboratoires publics ou privés. 


\section{The All-Seeing Eye of Resonant Auger}

\section{Electron Spectroscopy: A Study on Aqueous Solution Using Tender X-Rays}

Tsveta Miteva, ${ }^{* \dagger \dagger}$ Nikolai V. Kryzhevoi, ${ }^{\ddagger}$ Nicolas Sisourat, ${ }^{\dagger}$ Christophe Nicolas, ${ }^{\uparrow}$ Wandared Pokapanich,§ Thanit Saisopa," Prayoon Songsiriritthigul, " Yuttakarn Rattanachai, ${ }^{\perp}$ Andreas Dreuw, $\#$ Jan Wenzel, \# Jérôme Palaudoux, ${ }^{\dagger}$ Gunnar Öhrwall, ${ }^{@}$ Ralph Püttner, ${ }^{\triangle}$ Lorenz S. Cederbaum,,${ }^{\ddagger}$ Jean-Pascal Rueff,,$\uparrow$ and Denis Céolin*,

$\dagger$ †Sorbonne Université, CNRS, Laboratoire de Chimie Physique Matière et Rayonnement, UMR 7614, F-75005 Paris, France

$\ddagger$ Theoretische Chemie, Physikalisch-Chemisches Institut, Universität Heidelberg, Im Neuenheimer Feld 229, D-69120 Heidelberg, Germany

ๆSynchrotron SOLEIL, l'Orme des Merisiers, Saint-Aubin, F-91192 Gif-sur-Yvette Cedex,

France

§Faculty of Science, Nakhon Phanom University, Nakhon Phanom 48000, Thailand

||School of Physics, Suranaree University of Technology, Nakhon Ratchasima 30000, Thailand

$\perp$ Department of Applied Physics, Faculty of Sciences and Liberal Arts, Rajamangala

University of Technology Isan, Nakhon Ratchasima 30000, Thailand

\#Interdisciplinary Center for Scientific Computing, Ruprecht-Karls University, Im

Neuenheimer Feld 205A, D-69120 Heidelberg, Germany

@MAX IV Laboratory, Lund University, P.O. Box 118, SE-22100 Lund, Sweden

$\triangle$ Fachbereich Physik, Freie Universität Berlin, Arnimallee 14, D-14195, Berlin, Germany

E-mail: miteva.tsveta@gmail.com; denis.ceolin@synchrotron-soleil.fr 


\begin{abstract}
X-ray absorption and Auger electron spectroscopies are demonstrated to be powerful tools to unravel the electronic structure of solvated ions. In this work for the first time we use a combination of these methods in the tender $\mathrm{x}$-ray regime. This allowed us to address electronic transitions from deep core levels, to probe environmental effects, specifically in the bulk of the solution since the created energetic Auger electrons possess large mean free paths, and moreover, to obtain dynamical information about the ultrafast delocalization of the core-excited electron. In the considered exemplary aqueous $\mathrm{KCl}$ solution the solvated isoelectronic $\mathrm{K}^{+}$and $\mathrm{Cl}^{-}$ions exhibit notably different Auger electron spectra as a function of the photon energy. The differences appear due to dipole-forbidden transitions in aqueous $\mathrm{K}^{+}$whose occurrence, according to the performed $a b$ initio calculations, becomes possible only in the presence of solvent water molecules.
\end{abstract}

\title{
Graphical TOC Entry
}

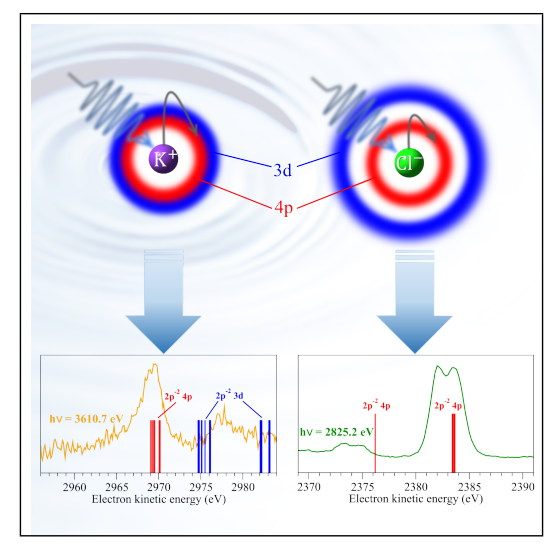

\section{Keywords}

Solvated ions, Auger electron spectroscopy, x-ray absorption spectroscopy 
Understanding how atoms or molecules respond to irradiation with x-rays gives insight into the structure of solutions (Ref. ${ }^{1}$ and references therein), and the mechanisms of radiation damage ${ }^{2-4}$. Depending on the photon energy, the absorption of an x-ray photon results in the population of core-excited or core-ionized states. The relaxation of these highly energetic states involves an ultrafast cascade of intraatomic processes, such as radiative and Auger decays, and it depends on the character of the initially populated states ${ }^{5-12}$. Furthermore, if the initially excited or ionized species is embedded in an environment, interatomic processes are possible ${ }^{4,13-16}$.

X-ray absorption spectroscopy (XAS) in the soft x-ray regime is a powerful tool to describe core-excited states of a specific atom and thus to probe the local environment surrounding the target atom by measuring its influence on the electronic structure of the atom. In the tender and hard $\mathrm{x}$-ray regimes, these core-excited states overlap significantly due to the lifetime broadening, rendering studies on the influence of the environment difficult. This challenge can be overcome by detecting the electrons originating from the subsequent resonant Auger decay, which allows one to separate the overlapping states ${ }^{17,18}$. With our recently commissioned microjet setup dedicated to the study of liquids by electron spectroscopy techniques using tender $\mathrm{x}$-rays ${ }^{19,20}$, we can now probe much deeper core levels and corresponding fast Auger electrons. This allows us to focus our investigations on the liquid bulk by strongly reducing the specific interface contributions, and also to access ultrafast dynamical processes owing to the very short lifetimes of the corresponding core-excited states.

In this work we combine Auger electron spectroscopy (AES) together with XAS in the tender x-ray regime to study the electronic decay processes following x-ray absorption of aqueous potassium chloride at the $\mathrm{K}$-edges of both $\mathrm{K}^{+}$and $\mathrm{Cl}^{-}$(schematically presented in Fig. 1). In particular, we demonstrate experimentally that at photon energies below the K-edges of the two ions, core-excited states are populated. These states undergo resonant Auger decay within less than $1 \mathrm{fs}^{16}$. In both ions, there is a competition between resonant Auger decay and delocalization of the excited electron. Using the core-hole clock method 
we show that in $\mathrm{Cl}^{-}$the delocalization time for the $1 \mathrm{~s}^{-1} 4 \mathrm{p}$ resonance is of the same order as that of the resonant Auger process, whereas in $\mathrm{K}^{+}$the delocalization is expected to be slower. Although the $\mathrm{K}^{+}$and $\mathrm{Cl}^{-}$ions are isoelectronic, they have different fingerprints in the resonant Auger spectra. Our analysis reveals that these differences result to a large extent from different electronic structures of the two ions, thus confirming that the combination of XAS and AES techniques is a sensitive probe of the electronic structure of solutions.
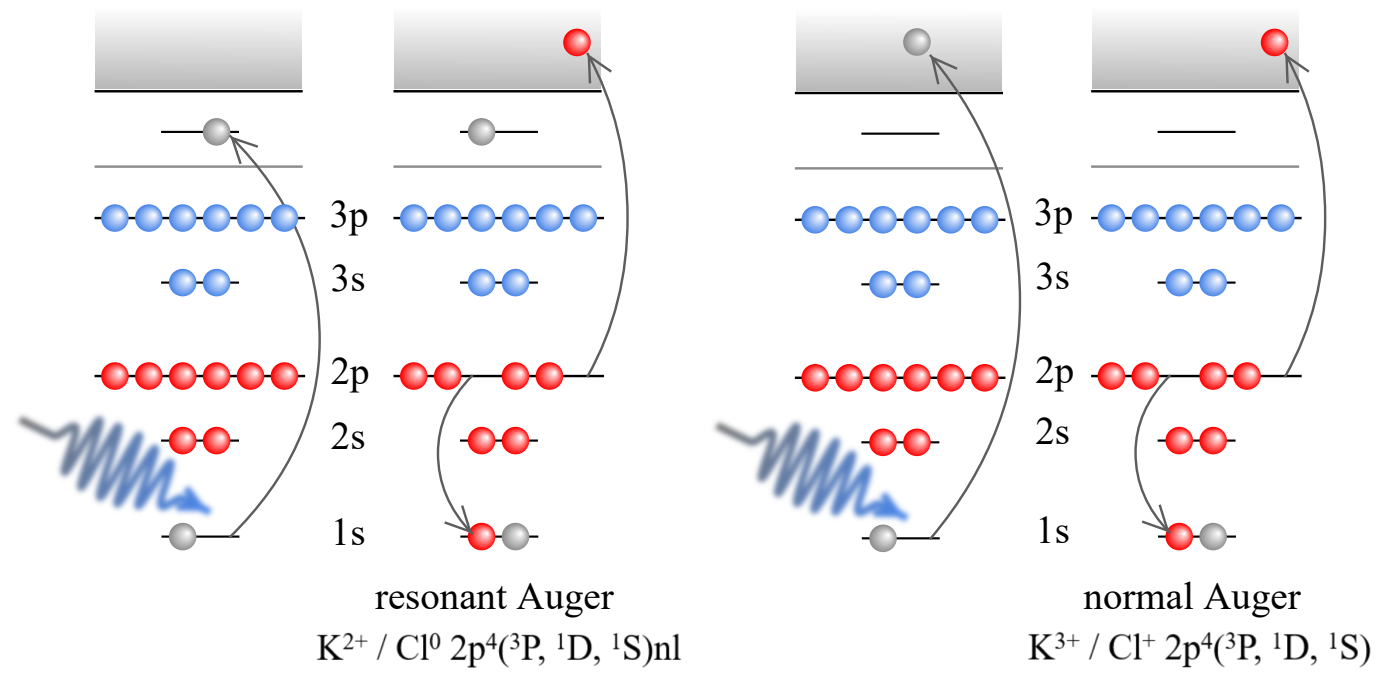

Figure 1: Schematic representation of the resonant (left) and normal (right) Auger processes of the isoelectronic $\mathrm{K}^{+}$and $\mathrm{Cl}^{-}$ions.

The photon-energy dependent resonant and normal Auger spectra of $\mathrm{K}_{\mathrm{aq}}^{+}$and $\mathrm{Cl}_{\mathrm{aq}}^{-}$are shown in Figs. 2 and 3 as 2D maps where the Auger intensities are illustrated by a color code. These spectra were measured using a newly operational microjet setup designed for the HAXPES end station of the GALAXIES beamline at the synchrotron radiation facility SOLEIL in France ${ }^{19,20}$; for details, see Supplementary Information (SI). The $\mathrm{KL}_{2,3} \mathrm{~L}_{2,3}$ normal Auger decay leads to the population of the $2 \mathrm{p}^{-2}\left({ }^{3} \mathrm{P},{ }^{1} \mathrm{D},{ }^{1} \mathrm{~S}\right)$ final states. For both $\mathrm{K}^{+}$and $\mathrm{Cl}^{-}$, the experimentally observed transitions are to the $2 \mathrm{p}^{-2}\left({ }^{1} \mathrm{D},{ }^{1} \mathrm{~S}\right)$ final states, whereas the transitions to ${ }^{3} \mathrm{P}$ final states are weak since they are forbidden in LS coupling (see Figs. 2(a) and $3(\mathrm{a}))$. In addition, the $2 \mathrm{p}^{-2}\left({ }^{1} \mathrm{D}\right)$ main line of $\mathrm{K}^{+}$exhibits a low-energy shoulder labeled A whose origin will be discussed below. Close to threshold the $\mathrm{KL}_{2,3} \mathrm{~L}_{2,3}$ normal Auger 
lines are asymmetric (see Figs. 2(c) and 3(c)) and also shifted to higher kinetic energies as compared to the spectra reported in ${ }^{16}$. This is due to post-collision interaction ${ }^{21,22}$ discussed in more detail in the SI.

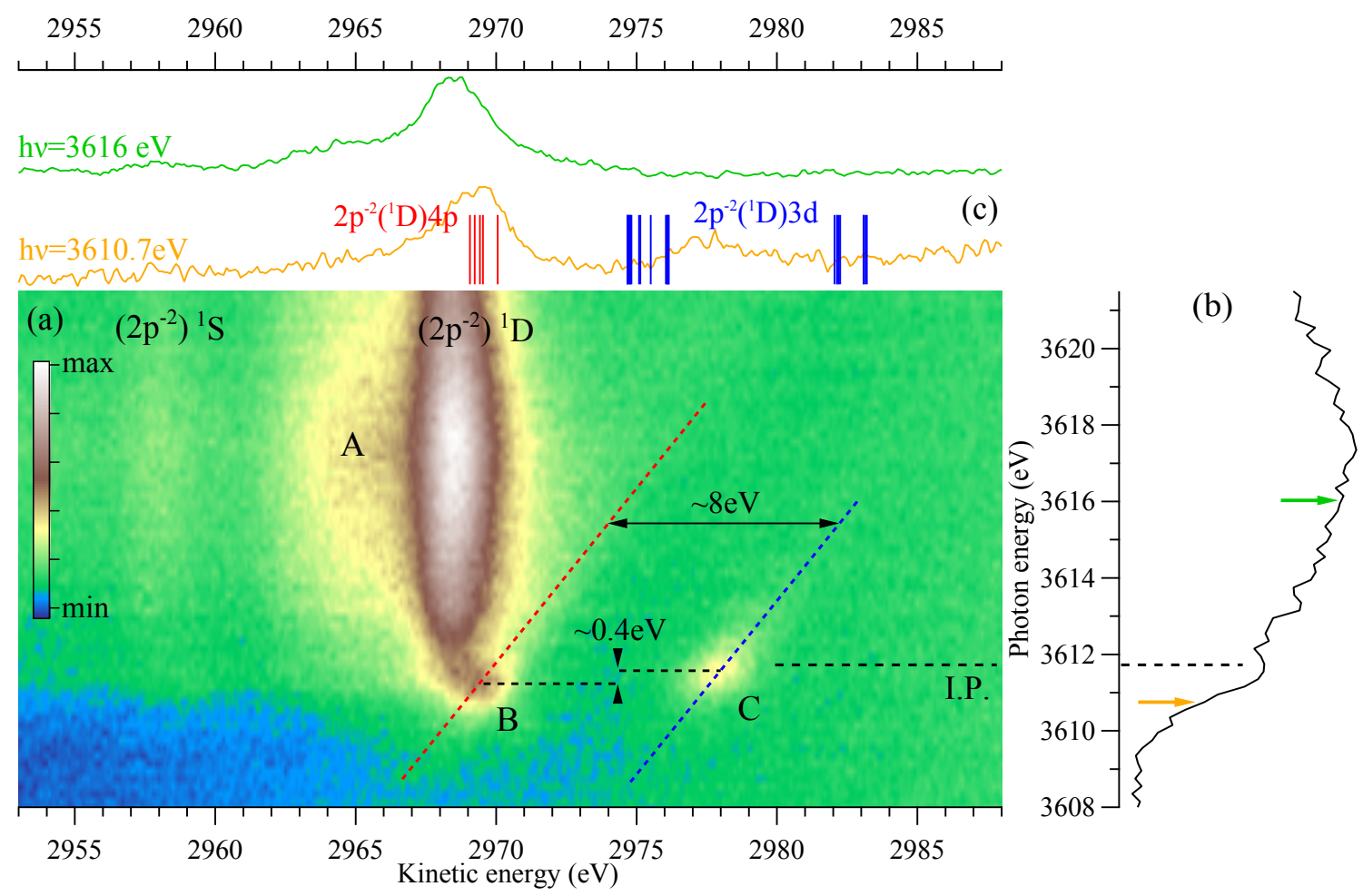

Figure 2: (a) 2D map showing the kinetic energy of the electrons emitted in $\mathrm{KL}_{2,3} \mathrm{~L}_{2,3}$ Auger decay vs the photon energy in the vicinity of the $\mathrm{K}$-edge of aqueous $\mathrm{K}^{+}$. The features $\mathrm{A}$, $\mathrm{B}$ and $\mathrm{C}$ are discussed in the text. (b) Experimental partial electron yield spectrum of $\mathrm{K}^{+}$ obtained after integrating over the kinetic energies of the Auger electrons. (c) Auger spectra at photon energies $3610.7 \mathrm{eV}$ and $3616 \mathrm{eV}$. The vertical bars in the resonant Auger spectrum measured at $3610.7 \mathrm{eV}$ indicate the spectator Auger energies of the calculated doublet $2 \mathrm{p}^{-2}$ $3 \mathrm{~d}$ (blue) and $2 \mathrm{p}^{-2} 4 \mathrm{p}$ (red) states of $\mathrm{K}^{+}\left(\mathrm{H}_{2} \mathrm{O}\right)_{6}$.

In the pre-edge regions of the XA spectra of $\mathrm{K}^{+}$and $\mathrm{Cl}^{-}$displayed on Figs. 2(b) and 3(b), no core-excited states are visible due to their lifetime broadening and energetic proximity to the ionization threshold. These states can, however, be identified by their resonant Auger features, which disperse with photon energy. These features are indicated by diagonal dashed lines in Figs. 2(a) and 3(a). To assign these features, we calculated the XA spectra, representing the initial states, and the final states of the Auger process.

The XA spectra in the region of the lowest core-excited states of isolated $\mathrm{K}^{+}$and $\mathrm{Cl}^{-}$and 


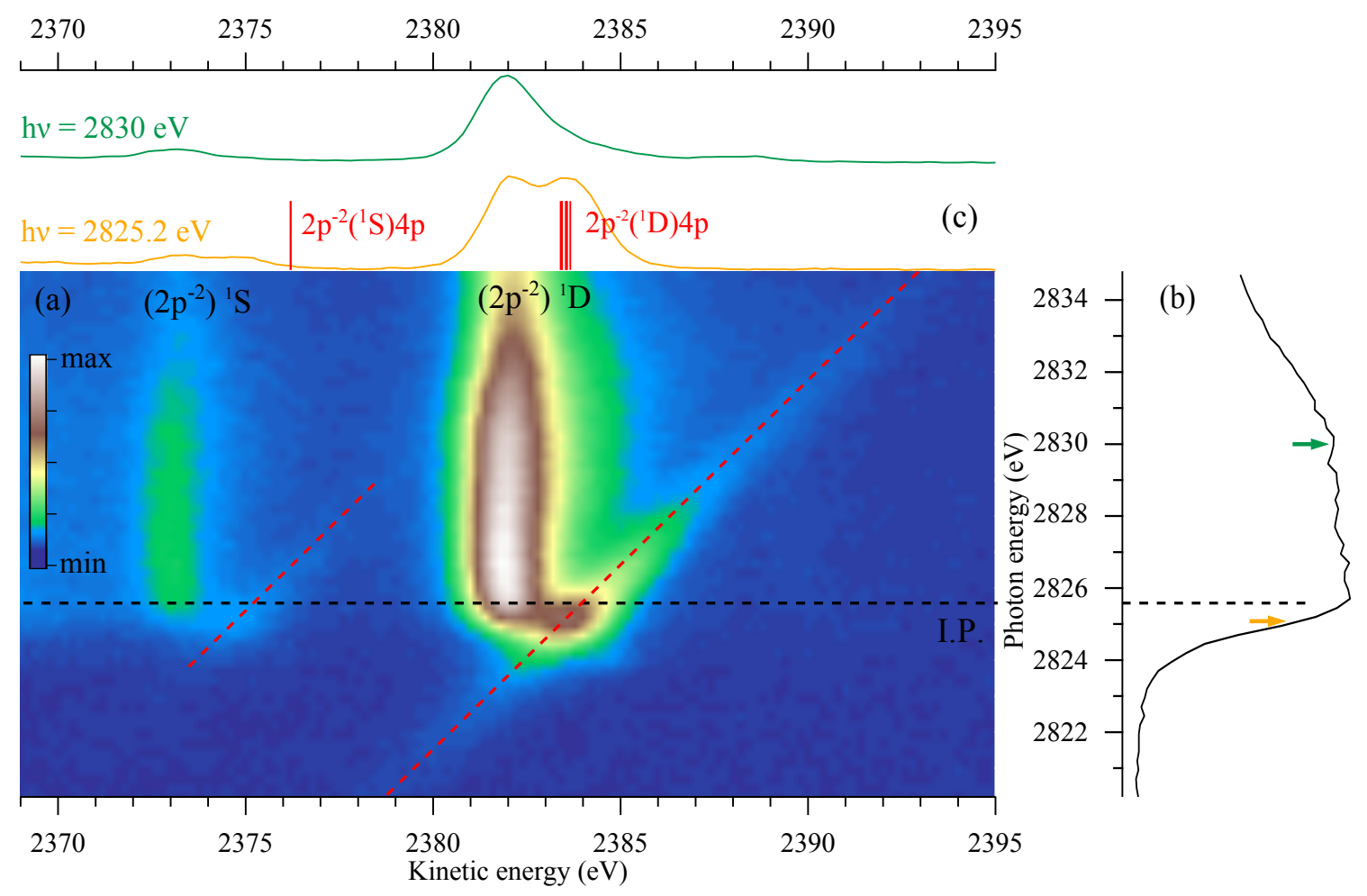

Figure 3: (a) 2D map showing the kinetic energy of the electrons emitted in $\mathrm{KL}_{2,3} \mathrm{~L}_{2,3}$ Auger decay vs the photon energy in the vicinity of the K-edge of aqueous $\mathrm{Cl}^{-}$. (b) Experimental partial electron yield spectrum of $\mathrm{Cl}^{-}$obtained after integrating over the kinetic energies of the Auger electrons. (c) Auger spectra at photon energies $2825.2 \mathrm{eV}$ and $2830.0 \mathrm{eV}$. The vertical bars in the resonant Auger spectrum at $2825.2 \mathrm{eV}$ indicate the the spectator Auger energies of the calculated doublet $2 \mathrm{p}^{-2} 4 \mathrm{p}$ states of $\mathrm{Cl}^{-}\left(\mathrm{H}_{2} \mathrm{O}\right)_{6}$.

their hexa-coordinated clusters representing $\mathrm{K}_{\mathrm{aq}}^{+}$and $\mathrm{Cl}_{\mathrm{aq}}^{-}$were calculated with the algebraic diagrammatic construction method for the polarization propagator ${ }^{23}$ within the core-valence separation approximation ${ }^{24-26}(\mathrm{CVS}-\mathrm{ADC}(2) \mathrm{x})$ as implemented in the Q-Chem package ${ }^{27-30}$ (see SI for details). The theoretical XA spectra of the isolated ions (Fig. 4(a),(b)) show the two dipole-allowed states, $1 \mathrm{~s}^{-1} 4 \mathrm{p}$ and $1 \mathrm{~s}^{-1} 5 \mathrm{p}$, which are split by $4.3 \mathrm{eV}$ and $10.8 \mathrm{eV}$ in $\mathrm{K}^{+}$and $\mathrm{Cl}^{-}$, respectively. The excitation energies of the dipole-forbidden $1 \mathrm{~s}^{-1} 3 \mathrm{~d}$ states are marked with blue crosses. Their positions relative to the $1 \mathrm{~s}^{-1} 4 \mathrm{p}$ states in $\mathrm{K}^{+}$and $\mathrm{Cl}^{-}$is different and as discussed below, this is important for understanding the resonant Auger features of $\mathrm{K}^{+}$. Upon addition of water molecules, the degeneracy of the states is lifted and they interact with other states of the ion or the neighboring water molecules. Thus, 
dipole-forbidden states acquire intensity in the cluster. A similar effect was observed in the XA spectra of microsolvated clusters of $\mathrm{Na}^{+}$and $\mathrm{Mg}^{2+31}$. The resulting spectra with the lowest resonances shifted to the experimental value are shown in Fig. 4(c),(d), together with the experimentally obtained ionization energies. In particular, the lowest peak in the XA spectrum of the 6-coordinated $\mathrm{K}^{+}$cluster contains three states (Fig. 4(c)). The lowestand highest-lying states are split by approximately $0.5 \mathrm{eV}$ and they have a mixed $4 \mathrm{p}$ and $5 \mathrm{p}$ character while the low-intensity state in between has a predominantly $1 \mathrm{~s}^{-1} 3 \mathrm{~d}$ character. In the hexa-coordinated cluster of $\mathrm{Cl}^{-}$, the solvent molecules have little influence on the position and character of the first state - it has mainly $\mathrm{Cl}^{-} 1 \mathrm{~s}^{-1} 4 \mathrm{p}$ character with some admixture of states of the nearest water molecules (Fig. 4(d)).

We also computed the lowest doublet states of the type $\mathrm{K}^{2+}\left[2 \mathrm{p}^{-2} \mathrm{nl}\right]\left(\mathrm{H}_{2} \mathrm{O}\right)_{6}$ and $\mathrm{Cl}^{0}\left[2 \mathrm{p}^{-2} \mathrm{nl}\right]\left(\mathrm{H}_{2} \mathrm{O}\right)_{6}$. They represent the final states of the spectator Auger decay, which is the predominant decay process for the low-lying core-excited states in isoelectronic argon ${ }^{32}$. The calculations were performed at the Configuration Interaction Singles (CIS) level using the GAMESS-US package $^{33-35}$ (see SI for details). The energy positions of the states (see bars on Figs. 2(c) and $3(\mathrm{c}))$ are adjusted to the kinetic-energy scale of the Auger spectra of both ions such that the lowest $2 \mathrm{p}^{-2}\left({ }^{1} \mathrm{D}\right) 4 \mathrm{p}$ states coincide with the maxima of the dipsersive features close to the ${ }^{1} \mathrm{D}$ main line.

In the following we assign the dispersive features on Figs. 2(a) and 3(a). In the 2D map of $\mathrm{Cl}^{-}$two dispersive resonant Auger features are visible. Both of them exhibit a maximum at $h \nu=2825.2 \mathrm{eV}$, i.e. $\cong 200 \mathrm{meV}$ below the ionization threshold. The former value agrees well with the position of the $1 \mathrm{~s}^{-1} 4 \mathrm{p}$ excitation determined from $\mathrm{Cl}$ K-edge XAS experiments on hydrated $\mathrm{Mg}$ and $\mathrm{Sr}$ chlorides ${ }^{36}$ and metalchloride complexes ${ }^{37}$. Moreover, the maxima in the kinetic energies of these dispersive features are split by $\cong 8.5 \mathrm{eV}$, which is in line with the calculated value of $\cong 7 \mathrm{eV}$ for the splitting between the $2 \mathrm{p}^{-2}\left({ }^{1} \mathrm{~S}\right) 4 \mathrm{p}$ and $2 \mathrm{p}^{-2}\left({ }^{1} \mathrm{D}\right) 4 \mathrm{p}$ final states. Consequently, we assign these features as originating from the resonant Auger decay of the $1 \mathrm{~s}^{-1} 4 \mathrm{p}$ excitation to the $2 \mathrm{p}^{-2}\left({ }^{1} \mathrm{~S},{ }^{1} \mathrm{D}\right) 4 \mathrm{p}$ final states. 
The 2D map of $\mathrm{K}^{+}$shown in Fig. 2(a) also displays two dispersive features. The line denoted as B exhibits a maximum at $\mathrm{h} \nu=3611.2 \mathrm{eV}$ and $E_{\text {kin }}=2969.2 \mathrm{eV}$, while the line labeled C exhibits a maximum at $\mathrm{h} \nu=3611.6 \mathrm{eV}$ and $E_{\text {kin }}=2978.1 \mathrm{eV}$. The observed energy positions relative to the $\mathrm{K}^{+} 1 \mathrm{~s}^{-1}$ threshold in combination with the relative energy position of the $2 \mathrm{p}^{-2} \mathrm{nl}$ states suggest that feature $\mathrm{B}$ is a result of resonant Auger decay of the $1 \mathrm{~s}^{-1} 4 \mathrm{p}$ excitation to the $2 \mathrm{p}^{-2}\left({ }^{1} \mathrm{D}\right) 4 \mathrm{p}$ final state, whereas feature $\mathrm{C}$ originates from the $1 \mathrm{~s}^{-1} 3 \mathrm{~d} \rightarrow$ $2 \mathrm{p}^{-2}\left({ }^{1} \mathrm{D}\right) 3 \mathrm{~d}$ resonant Auger transition. The latter is dipole-forbidden in the isolated ion, which explains the low intensity of feature C. Another argument in favor of this assignment is the energy difference between the spectral features A and C, which matches well the lowest ionization potential of liquid water $\mathrm{I}_{\mathrm{aq}} \cong 11.16 \mathrm{eV} \cdot{ }^{38}$ Feature $\mathrm{A}$ is assigned to a charge transfer from a water molecule $\mathrm{W}$ to the $3 \mathrm{~d}$ orbital of $\mathrm{K}^{+}$during the Auger decay, i.e. $\mathrm{K}^{2+}\left(1 \mathrm{~s}^{-1}\right) \rightarrow$ $\mathrm{K}^{2+}\left(2 \mathrm{p}^{-2} 3 \mathrm{~d}\right) \mathrm{W}^{+16}$, so that its energy position should be lower by $\mathrm{I}_{\mathrm{aq}}$ if we take into account the small energy separation of the $1 \mathrm{~s}^{-1} 3 \mathrm{~d}$ excitation from threshold. No dispersive features related to the $2 \mathrm{p}^{-2}\left({ }^{1} \mathrm{~S}\right)$ parent state are observed in the $2 \mathrm{D}$ map due to the high intensity and broadening of shoulder A.

We note that the resonances of $\mathrm{K}_{\mathrm{aq}}^{+}$and $\mathrm{Cl}_{\mathrm{aq}}^{-}$calculated to be above the corresponding ionization threshold (Fig. 4(c,d)) are not experimentally observed. This might be due to the fact that the corresponding resonant Auger spectra cannot be separated energetically from the more intense normal Auger main lines.

An important aspect of the study of core-excited states in aqueous solutions is the effect of ultrafast delocalization of the excited electron which competes with the resonant Auger decay $^{40,41}$. The photon-energy dependent Auger spectra also contain information about the delocalization time thus providing a convenient alternative to the more challenging timedomain experiments in the $1 \mathrm{fs}$ regime. To estimate the photon-energy dependent delocalization time of the core-excited electron, $\tau_{\mathrm{CT}}(\mathrm{h} \nu)$, we used the core-hole clock method. ${ }^{17,42-45}$ Within this method, $\tau_{\mathrm{CT}}(\mathrm{h} \nu)$ can be determined from the lifetime of the core hole $\tau_{\mathrm{c}}$ and the ratio of the intensities of the normal $(d)$ and resonant $(l)$ Auger peaks according to 


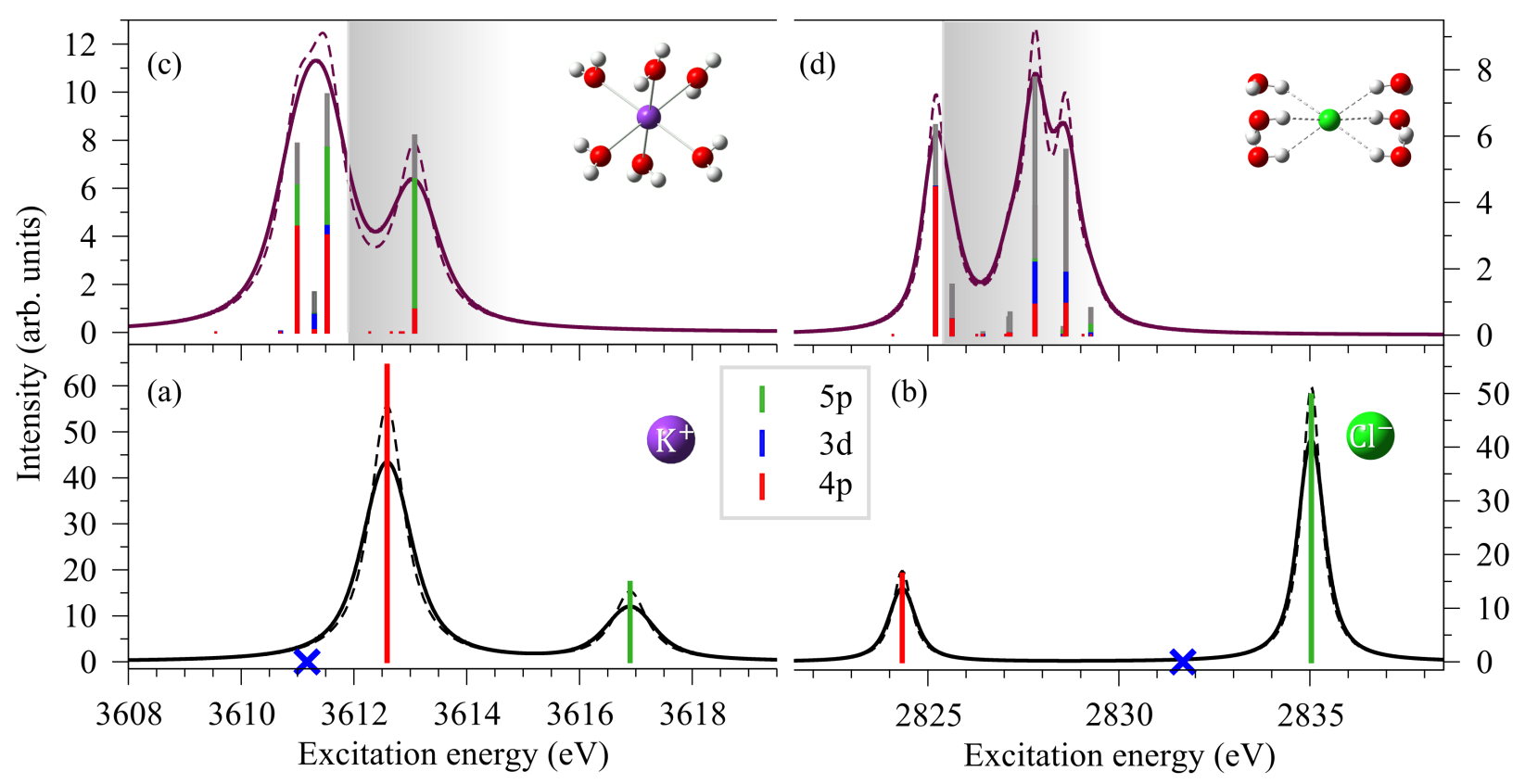

Figure 4: XA spectra of the lowest K-shell resonant transitions in the isolated $\mathrm{K}^{+}$(a) and $\mathrm{Cl}^{-}$ (b) ions and their 6-coordinated clusters, (c) and (d). For comparison with the experiment, the theoretical stick spectra are convolved with a Lorentzian of FWHM $0.74 \mathrm{eV}$ and $0.62 \mathrm{eV}$ representing the lifetime broadening of $\mathrm{K}^{+}$and $\mathrm{Cl}^{-39}$ (dashed lines) and a Voigt profile (solid line) to account for both the lifetime and the experimental broadening (see text). The colors in the stick spectrum represent the projections of the singly-occupied natural orbitals (SONOs) of the core-excited 6-coordinated clusters on the basis of SONOs belonging to the $1 \mathrm{~s}^{-1} 3 \mathrm{~d}, 1 \mathrm{~s}^{-1} 4 \mathrm{p}$, and $1 \mathrm{~s}^{-1} 5 \mathrm{p}$ states of the isolated ions. The remaining contributions from higher-lying atomic core excitations or from excitations to the solvent molecules are depicted as grey sticks. The theoretical XA spectra of both $\mathrm{K}^{+}$and $\mathrm{Cl}^{-}$were shifted to higher photon energies such that the energies of the lowest core-excited states correspond to the experimentally determined ones. The darker edge of the grey boxes indicates the ionization threshold as obtained in the experiment.

the relation $\tau_{\mathrm{CT}}=\tau_{\mathrm{c}} l(\mathrm{~h} \nu) / d(\mathrm{~h} \nu)^{17,42-45}$. In the case of $\mathrm{Cl}^{-}$, we performed the same data treatment as in Ref. ${ }^{32}$ to extract the intensities $l(\mathrm{~h} \nu)$ and $d(\mathrm{~h} \nu)$ (see Fig. 2 in the SI). At the specific photon energy of $\mathrm{h} \nu=2825.2 \mathrm{eV}$, i.e. at the maximum of the lowest core excitation $1 \mathrm{~s}^{-1} 4 \mathrm{p}, \tau_{\mathrm{CT}}$ is of the same order as the Auger lifetime, $\cong 1 \mathrm{fs}$. This is manifested as a double-peak structure in the Auger spectrum in the interval $\mathrm{E}_{k i n}=2380-2385 \mathrm{eV}$ (Fig. $3(\mathrm{c}))$. The position of the first peak coincides with the ${ }^{1} \mathrm{D}$ main line resulting from normal Auger decay, whereas the second peak at $2383.5 \mathrm{eV}$ corresponds to resonant Auger decay to the $2 \mathrm{p}^{-2}\left({ }^{1} \mathrm{D}\right) 4 \mathrm{p}$ states. The fast delocalization in this case is a result of the fact that the 
energy splitting between the $\mathrm{Cl}^{-}\left(1 \mathrm{~s}^{-1} 4 \mathrm{p}\right)$ resonance and the ionization threshold is $0.2 \mathrm{eV}$, and thus, smaller than the lifetime broadening of $0.62 \mathrm{eV}^{16}$.

For potassium, a comparable data treatment is more complicated due to the smaller splitting between the $1 \mathrm{~s}^{-1} \rightarrow 2 \mathrm{p}^{-2}\left({ }^{1} \mathrm{D}\right)$ normal Auger and $1 \mathrm{~s}^{-1} 4 \mathrm{p} \rightarrow 2 \mathrm{p}^{-2}\left({ }^{1} \mathrm{D}\right) 4 \mathrm{p}$ resonant Auger lines as well as the presence of contributions caused by charge transfer from the solvent. This hinders the extraction of reliable intensities for the different contributions visible in the 2D map (Fig. 2(a)), especially close to threshold in the kinetic energy region $2965-2970 \mathrm{eV}$. However, one can expect much less efficient delocalization in $\mathrm{K}^{+}$compared to $\mathrm{Cl}^{-}$because the lowest core-excited state appears $0.7 \mathrm{eV}$ below the ionization threshold compared to $0.2 \mathrm{eV}$ for chloride and, moreover, because the lifetime of the K1s core hole is shorter than that of chloride (0.9 vs. $1 \mathrm{fs}$ ).

In summary, we studied the electronic structure of aqueous solution of $\mathrm{KCl}$ at the $\mathrm{K}$ edges of both $\mathrm{K}_{\mathrm{aq}}^{+}$and $\mathrm{Cl}_{\mathrm{aq}}^{-}$by combining XAS and AES in the tender x-ray regime, and $a b$ initio calculations. The Auger electron spectra of both ions exhibit features of normal and resonant Auger processes. The spectator resonant Auger decay following the $1 \mathrm{~s}^{-1} 4 \mathrm{p}$ excitation proceeds similarly for both aqueous $\mathrm{K}^{+}$and $\mathrm{Cl}^{-}$resulting in dispersive lines with maxima close to the normal Auger features. However, there is a clear difference between the two ions due to the non-negligible excitation of the dipole-forbidden $1 \mathrm{~s}^{-1} 3 \mathrm{~d}$ state of $\mathrm{K}^{+}$in solution. The spectator Auger decay of this state produces an additional feature which is well separated from the remaining Auger features. Another substantial difference between the two ions is the time of delocalization of the core-excited electron at the pre-edge region. Using the core-hole clock method, we extracted information about the delocalization dynamics from the photon-energy dependent Auger spectra. In the case of $\mathrm{Cl}^{-}$, the resonant Auger decay and the delocalization of the excited electron occur on a comparable timescale, whereas in $\mathrm{K}^{+}$, a much less efficient delocalization is expected. These results are an important first step in the study of relaxation cascades triggered by x-ray photoabsorption in liquids. The Auger processes considered here are inevitably followed by multiple intra- and interatomic electronic 
decays, such as interatomic Coulombic decay (ICD) and electron-transfer mediated decay $(\mathrm{ETMD})^{4,15}$. As a result of the latter processes, genotoxic free radicals and slow electrons are formed in the vicinity of the metal center. The magnitude of the damage inflicted upon the environment and the energies of the emitted electrons depend on the initial Auger step, and can therefore be controlled by tuning the energy of the radiation. Consequently, the results of this work can have implications in understanding radiation chemistry and radiation damage in biologically relevant systems in which metallic centers are ubiquitous.

\section{Acknowledgement}

We thank Prof. Nobuhiro Kosugi and Dr. Matjaž Žitnik for the fruitful discussions. Experiments were performed at the GALAXIES beamline, SOLEIL Synchrotron, France (Proposal No. 20140160). The authors are grateful to the SOLEIL staff for assistance during the beamtime. This project has received funding from the Research Executive Agency (REA) under the European Union's Horizon 2020 research and innovation programme Grant agreement No. 705515. Campus France and the PHC SIAM exchange program are acknowledged for financial support (project No. 38282QB). L. S. Cederbaum and N. V. Kryzhevoi acknowledge the financial support of the European Research Council (ERC) (Advanced Investigator Grant No. 692657) and the Deutsche Forschungsgemeinschaft (DFG research unit 1789).

\section{Supporting Information Available}

- suppinfo.pdf: contains 1) a detailed description of the experiment, as well as the $a b$ initio calculations; 2) an explanation of the post-collision interaction shift observed in the experimental Auger spectra; 3) the radial density distributions of the core excited states of the bare ions; 4) the partial cross sections and charge transfer time extracted from the experimental 2D map near the Cl1s edge. 


\section{References}

(1) Smith, J. W.; Saykally, R. J. Soft X-ray Absorption Spectroscopy of Liquids and Solutions. Chem. Rev. 2017, 11\%, 13909-13934.

(2) O’Neill, P.; Stevens, D. L.; Garman, E. F. Physical and Chemical Considerations of Damage Induced in Protein Crystals by Synchrotron Radiation: a Radiation Chemical Perspective. J. Synchrotron Radiat. 2002, 9, 329-332.

(3) Carugo, O.; Carugo, K. D. When X-rays Modify the Protein Structure: Radiation Damage at Work. Trends Biochem. Sci. 2005, 30, 213-219.

(4) Stumpf, V.; Gokhberg, K.; Cederbaum, L. S. The Role of Metal Ions in X-Ray-Induced Photochemistry. Nat. Chem. 2016, 8, 237-241.

(5) Stoychev, S. D.; Kuleff, A. I.; Tarantelli, F.; Cederbaum, L. S. On the Interatomic Electronic Processes Following Auger Decay in Neon Dimer. J. Chem. Phys. 2008, 129, 074307.

(6) Demekhin, P. V.; Scheit, S.; Stoychev, S. D.; Cederbaum, L. S. Dynamics of Interatomic Coulombic Decay in a Ne Dimer Following the $K-L_{1} L_{2,3}\left({ }^{1} P\right)$ Auger Transition in the Ne Atom. Phys. Rev. A 2008, 78, 043421.

(7) Demekhin, P. V.; Chiang, Y.-C.; Stoychev, S. D.; Kolorenč, P.; Scheit, S.; Kuleff, A. I.; Tarantelli, F.; Cederbaum, L. S. Interatomic Coulombic Decay and its Dynamics in NeAr Following K-LL Auger Transition in the Ne Atom. J. Chem. Phys. 2009, 131, 104303.

(8) Ouchi, T.; Sakai, K.; Fukuzawa, H.; Higuchi, I.; Demekhin, P. V.; Chiang, Y.-C.; Stoychev, S. D.; Kuleff, A. I.; Mazza, T.; Schöffler, M. et al. Interatomic Coulombic Decay Following Ne 1s Auger Decay in NeAr. Phys. Rev. A 2011, 83, 053415. 
(9) Miteva, T.; Chiang, Y.-C.; Kolorenč, P.; Kuleff, A. I.; Cederbaum, L. S.; Gokhberg, K. The Effect of the Partner Atom on the Spectra of Interatomic Coulombic Decay Triggered by Resonant Auger Processes. J. Chem. Phys. 2014, 141, 164303.

(10) Travnikova, O.; Marchenko, T.; Goldsztejn, G.; Jänkälä, K.; Sisourat, N.; Carniato, S.; Guillemin, R.; Journel, L.; Céolin, D.; Püttner, R. et al. Hard-X-Ray-Induced Multistep Ultrafast Dissociation. Phys. Rev. Lett. 2016, 116, 213001.

(11) Gokhberg, K.; Kolorenč, P.; Kuleff, A. I.; Cederbaum, L. S. Site- and Energy-Selective Slow-Electron Production through Intermolecular Coulombic Decay. Nature 2014, 505, $661-663$.

(12) Trinter, F.; Schöffler, M. S.; Kim, H.-K.; Sturm, F. P.; Cole, K.; Neumann, N.; Vredenborg, A.; Williams, J.; Bocharova, I.; Guillemin, R. et al. Resonant Auger Decay Driving Intermolecular Coulombic Decay in Molecular Dimers. Nature 2014, 505, 664-666.

(13) Pokapanich, W.; Bergersen, H.; Bradeanu, I. L.; Marinho, R. R. T.; Lindblad, A.; Legendre, S.; Rosso, A.; Svensson, S.; Björneholm, O.; Tchaplyguine, M. et al. Auger Electron Spectroscopy as a Probe of the Solution of Aqueous Ions. J. Am. Chem. Soc. 2009, 131, 7264-7271.

(14) Pokapanich, W.; Kryzhevoi, N. V.; Ottosson, N.; Svensson, S.; Cederbaum, L. S.; Öhrwall, G.; Björneholm, O. Ionic-Charge Dependence of the Intermolecular Coulombic Decay Time-Scale for Aqueous Ions Probed by the Core-Hole Clock. J. Am. Chem. Soc. 2011, 133, 13430 .

(15) Unger, I.; Seidel, R.; Thürmer, S.; Pohl, M. N.; Aziz, E. F.; Cederbaum, L. S.; Muchová, E.; Slavíček, P.; Winter, B.; Kryzhevoi, N. V. Observation of Electron-TransferMediated Decay in Aqueous Solution. Nat. Chem. 2017, 9, 708.

(16) Céolin, D.; Kryzhevoi, N. V.; Nicolas, C.; Pokapanich, W.; Choksakulporn, S.; Songsiriritthigul, P.; Saisopa, T.; Rattanachai, Y.; Utsumi, Y.; Palaudoux, J. et al. 
Ultrafast Charge Transfer Processes Accompanying KLL Auger Decay in Aqueous KCl Solution. Phys. Rev. Lett. 2017, 119, 263003.

(17) Föhlisch, A.; Feulner, P.; Hennies, F.; Fink, A.; Menzel, D.; Sanchez-Portal, D.; Echenique, P. M.; Wurth, W. Direct Observation of Electron Dynamics in the Attosecond Domain. Nature 2005, 436, 373.

(18) Goldsztejn, G.; Marchenko, T.; Ceolin, D.; Journel, L.; Guillemin, R.; Rueff, J.-P.; Kushawaha, R. K.; Puttner, R.; Piancastelli, M. N.; Simon, M. Electronic StateLifetime Interference in Resonant Auger Spectra: a Tool to Disentangle Overlapping Core-Excited States. Phys. Chem. Chem. Phys. 2016, 18, 15133-15142.

(19) Céolin, D.; Ablett, J.; Prieur, D.; Moreno, T.; Rueff, J.-P.; Marchenko, T.; Journel, L.; Guillemin, R.; Pilette, B.; Marin, T. et al. Hard X-Ray Photoelectron Spectroscopy on the GALAXIES Beamline at the SOLEIL Synchrotron. J. Electron Spectrosc. Relat. Phenom. 2013, 190, Part B, 188 - 192.

(20) Rueff, J.-P.; Ablett, J. M.; Céolin, D.; Prieur, D.; Moreno, T.; Balédent, V.; LassalleKaiser, B.; Rault, J. E.; Simon, M.; Shukla, A. The GALAXIES Beamline at the SOLEIL Synchrotron: Inelastic X-Ray Scattering and Photoelectron Spectroscopy in the Hard X-Ray Range. J. Synchrotron Rad. 2015, 22, 175-179.

(21) Russek, A.; Mehlhorn, W. Post-Collision Interaction and the Auger Lineshape. J. Phys. B At. Mol. Opt. Phys. 1986, 19, 911.

(22) Guillemin, R.; Sheinerman, S.; Püttner, R.; Marchenko, T.; Goldsztejn, G.; Journel, L.; Kushawaha, R. K.; Céolin, D.; Piancastelli, M. N.; Simon, M. Postcollision Interaction Effects in KLL Auger Spectra Following Argon 1s Photoionization. Phys. Rev. A 2015, 92, 012503.

(23) Schirmer, J. Beyond the Random-Phase Approximation: a New Approximation Scheme for the Polarization Propagator. Phys. Rev. A 1982, 26, 2395-2416. 
(24) Barth, A.; Schirmer, J. Theoretical Core-Level Excitation Spectra of $\mathrm{N}_{2}$ and CO by a New Polarisation Propagator Method. J. Phys. B At. Mol. Opt. Phys. 1985, $18,867$.

(25) Cederbaum, L. S.; Domcke, W.; Schirmer, J. Many-Body Theory of Core Holes. Phys. Rev. A 1980, 22, 206-222.

(26) Barth, A.; Cederbaum, L. S. Many-Body Theory of Core-Valence Excitations. Phys. Rev. A 1981, 23, 1038-1061.

(27) Wenzel, J.; Wormit, M.; Dreuw, A. Calculating Core-Level Excitations and XRay Absorption Spectra of Medium-Sized Closed-Shell Molecules with the AlgebraicDiagrammatic Construction Scheme for the Polarization Propagator. J. Comp. Chem. 2014, 35, 1900-1915.

(28) Wenzel, J.; Wormit, M.; Dreuw, A. Calculating X-ray Absorption Spectra of Open-Shell Molecules with the Unrestricted Algebraic-Diagrammatic Construction Scheme for the Polarization Propagator. J. Chem. Theory Comput. 2014, 10, 4583-4598.

(29) Wormit, M.; Rehn, D. R.; Harbach, P. H.; Wenzel, J.; Krauter, C. M.; Epifanovsky, E.; Dreuw, A. Investigating Excited Electronic States using the Algebraic Diagrammatic Construction (ADC) Approach of the Polarisation Propagator. Mol. Phys. 2014, 112, $774-784$.

(30) Shao, Y.; Gan, Z.; Epifanovsky, E.; Gilbert, A. T.; Wormit, M.; Kussmann, J.; Lange, A. W.; Behn, A.; Deng, J.; Feng, X. et al. Advances in Molecular Quantum Chemistry Contained in the Q-Chem 4 Program Package. Mol. Phys. 2015, 113, 184215.

(31) Miteva, T.; Wenzel, J.; Klaiman, S.; Dreuw, A.; Gokhberg, K. X-Ray Absorption Spectra of Microsolvated Metal Cations. Phys. Chem. Chem. Phys. 2016, 18, 16671-16681. 
(32) Céolin, D.; Marchenko, T.; Guillemin, R.; Journel, L.; Kushawaha, R. K.; Carniato, S.; Huttula, S.-M.; Rueff, J. P.; Armen, G. B.; Piancastelli, M. N. et al. Auger ResonantRaman Study at the Ar K Edge as Probe of Electronic-State-Lifetime Interferences. Phys. Rev. A 2015, 91, 022502.

(33) Brooks, B. R.; Laidig, W. D.; Saxe, P.; Handy, N. C.; Schaefer III, H. F. The LoopDriven Graphical Unitary Group Approach: a Powerful Method for the Variational Description of Electron Correlation. Phys. Scr. 1980, 21, 312.

(34) Brooks, B. R.; Schaefer, H. F. The Graphical Unitary Group Approach to the Electron Correlation Problem. Methods and Preliminary Applications. J. Chem. Phys. 1979, $70,5092-5106$.

(35) Schmidt, M. W.; Baldridge, K. K.; Boatz, J. A.; Elbert, S. T.; Gordon, M. S.; Jensen, J. H.; Koseki, S.; Matsunaga, N.; Nguyen, K. A.; Su, S. et al. General Atomic and Molecular Electronic Structure System. J. Comp. Chem. 1993, 14, 1347-1363.

(36) Sugiura, C. Influence of Coordinating Water on the Chlorine K Absorption Spectra of Hydrated Metal Dichlorides: $\mathrm{MgCl}_{2} \cdot 6 \mathrm{H}_{2} \mathrm{O}$ and $\mathrm{SrCl}_{2} \cdot 6 \mathrm{H}_{2} \mathrm{O}$. J. Chem. Phys. 1982, r7, $681-682$.

(37) Shadle, S. E.; Hedman, B.; Hodgson, K. O.; Solomon, E. I. Ligand K-Edge X-Ray Absorption Spectroscopic Studies: Metal-Ligand Covalency in a Series of Transition Metal Tetrachlorides. J. Am. Chem. Soc. 1995, 117, 2259-2272.

(38) Winter, B.; Weber, R.; Widdra, W.; Dittmar, M.; Faubel, M.; Hertel, I. V. Full Valence Band Photoemission from Liquid Water Using EUV Synchrotron Radiation. J. Phys. Chem. A 2004, 108, 2625-2632.

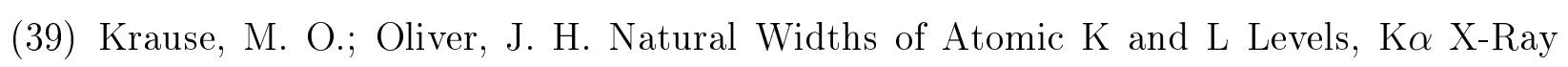
Lines and Several KLL Auger Lines. J. Phys. Chem. Ref. Data 1979, 8, 329-338. 
(40) Nordlund, D.; Ogasawara, H.; Bluhm, H.; Takahashi, O.; Odelius, M.; Nagasono, M.; Pettersson, L. G. M.; Nilsson, A. Probing the Electron Delocalization in Liquid Water and Ice at Attosecond Time Scales. Phys. Rev. Lett. 2007, 99, 217406.

(41) Ottosson, N.; Öhrwall, G.; Björneholm, O. Ultrafast Charge Delocalization Dynamics in Aqueous Electrolytes: New Insights from Auger Electron Spectroscopy. Chem. Phys. Lett. 2012, 543, $1-11$.

(42) Björneholm, O.; Nilsson, A.; Sandell, A.; Hernnäs, B.; Mrtensson, N. Determination of Time Scales for Charge-Transfer Screening in Physisorbed Molecules. Phys. Rev. Lett. 1992, 68, 1892-1895.

(43) Karis, O.; Nilsson, A.; Weinelt, M.; Wiell, T.; Puglia, C.; Wassdahl, N.; Mårtensson, N.; Samant, M.; Stöhr, J. One-Step and Two-Step Description of Deexcitation Processes in Weakly Interacting Systems. Phys. Rev. Lett. 1996, 76, 1380-1383.

(44) Wurth, W.; Menzel, D. Ultrafast Electron Dynamics at Surfaces Probed by Resonant Auger Spectroscopy. Chem. Phys. 2000, 251, 141 - 149.

(45) Brühwiler, P. A.; Karis, O.; Mårtensson, N. Charge-Transfer Dynamics Studied Using Resonant Core Spectroscopies. Rev. Mod. Phys. 2002, 74, 703-740. 